\title{
Is There an Inflation Puzzle?
}

Cara S. L own and Robert W. Rich*

istorically, inflation has followed a fairly predictable course in relation to the business cycle. Inflation typically rises during an economic expansion, peaks slightly after the onset of recession, and then continues to decline through the first year or two of recovery. During the present U.S. expansion, however, inflation has taken a markedly different path. Although more than six years have passed since the 1990-91 recession, inflation in the core CPI (the consumer price index excluding its volatile food and energy components) has yet to accelerate (Chart 1). Moreover, during the last three years, inflation has remained stable despite projections of higher expected inflation from the Blue Chip Consensus forecast and contrary to traditional signals such as the run-up in commodity prices experienced from late 1993 to early 1995.

* Cara S. Lown is a research officer and Robert W. Rich an economist at the Federal Reserve Bank of $\mathrm{N}$ ew $\mathrm{Y}$ ork.
Economists and policymakers have referred to the restrained behavior of prices during this long expansion as an "inflation puzzle." In a recent interview, Robert $T$. Parry, president of the Federal Reserve Bank of San Francisco, commented, "I have a question mark, and it leads me to recommend vigilance with regard to inflation, but I do have to note that things have turned out well.... [W e've] either been lucky, in which case the old relationships will reassert themselves, or [we've] got a new regime under way. And I don't think we know enough at this point to know which of those two things is operative."1 As Parry suggests, two different types of explanations could account for the recent behavior of inflation. The failure of inflation to accelerate may reflect the effects of temporary factors unique to this expansion. Alternatively, the unexpectedly low level of inflation may indicate a permanent change in the way inflation reacts to economic growth and other related variables.

Each of these explanations holds important implications for the conduct of monetary policy. The Phillips 
curve, the principal tool used by economists to explain inflation, has been subject to systematic overprediction errors during the past few years. If these errors reflect the influence of temporary factors, then the Phillips curve relationship should ultimately regain its stability. $\mathrm{H}$ owever, if these errors reflect a permanent change in the dynamics of the inflation process, then economists could no longer view the Phillips curve as a reliable guide in forecasting inflation.

Because labor costs are an important factor in determining prices, the recent slowdown in compensation growth has been cited in both types of explanations for the inflation puzzle. Some commentators argue that this slowdown in compensation growth, attributable largely to declining benefit costs, has acted as a supply shock and has temporarily lowered inflation relative to its historical proximate determinants. Others contend that a permanent change in compensation growth, resulting from heightened job insecurity and its constrictive effect on wage growth, has led to a fundamental shift in the inflation process.

This article explores the inflation puzzle and investigates whether compensation has acted as either a temporary restraint on inflation or as the underlying source of a new inflation regime. ${ }^{2}$ After reviewing the recent

Chart 1

Core CPI

Percentage Change from a Y ear Ago

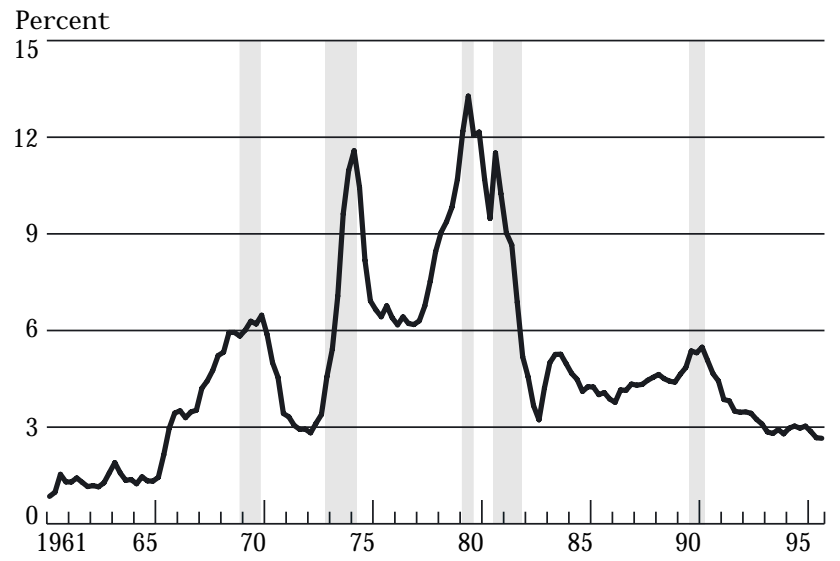

Source: U.S. Department of Labor, Bureau of Labor Statistics. $\mathrm{N}$ ote: Shaded areas indicate periods designated recessions by the $\mathrm{N}$ ational Bureau of Economic Research. behavior of inflation, we specify and estimate a traditional price-inflation Phillips curve model over the 1965-96 period. Our results show that in late 1993 the model begins to systematically overpredict inflation and appears to break down.

We then modify our traditional Phillips curve specification by incorporating compensation growth as an additional determinant of inflation. W ith this variable, the model's explanatory power improves significantly, and it tracks inflation much more accurately over the current

Our findings indicate that compensation growth has been weak during this expansion, especially from late 1992 through early 1995, a period that corresponds to the observed breakdown in our traditional Phillips curve specification.

expansion. The restored stability of the model appears to rule out the view that inflation's recent behavior reflects a fundamental shift in the inflation process.

Finally, we specify and estimate a wage-inflation Phillips curve model quantifying the restraint in compensation growth over the post-1991 period. Our findings indicate that compensation growth has been weak during this expansion, especially from late 1992 through early 1995, a period that corresponds to the observed breakdown in our traditional Phillips curve specification. This coincidence further supports our conclusion that compensation's slow growth has temporarily restrained inflation during this expansion.

\section{THE EMERGEN CE OF THE IN FLATION PUZZLE}

Contrary to expectations, inflation has not accelerated since the end of the 1990-91 recession. Yet variables commonly regarded as inflation indicators have remained at levels that 
usually coincide with an inflation pickup. The level of the actual unemployment rate relative to the nonaccelerating inflation rate of unemployment (N AIRU) is one such variable. The NAIRU represents the rate of unemployment that is consistent with stable inflation. U nemployment rates below (above) the NAIRU are thought to signal higher (lower) inflation in wages and prices. As the upper panel of Chart 2 shows, the unemployment rate has been below 6 percent - the consensus estimate of the N AIRU at the beginning of this expansion-since late 1994. Even if the NAIRU has declined below 6 percent during the 1990s, as some analysts argue, there is little direct evidence suggesting that it has tracked the unemployment rate or fallen low enough to be consistent with the level of inflation observed since 1995 . $^{3}$

Like the NAIRU, the capacity utilization rate has stayed at levels that typically signal higher future inflation (bottom panel of Chart 2). In the past, capacity utilization

Chart 2

Unempl oyment and Capacity Utilization Rates
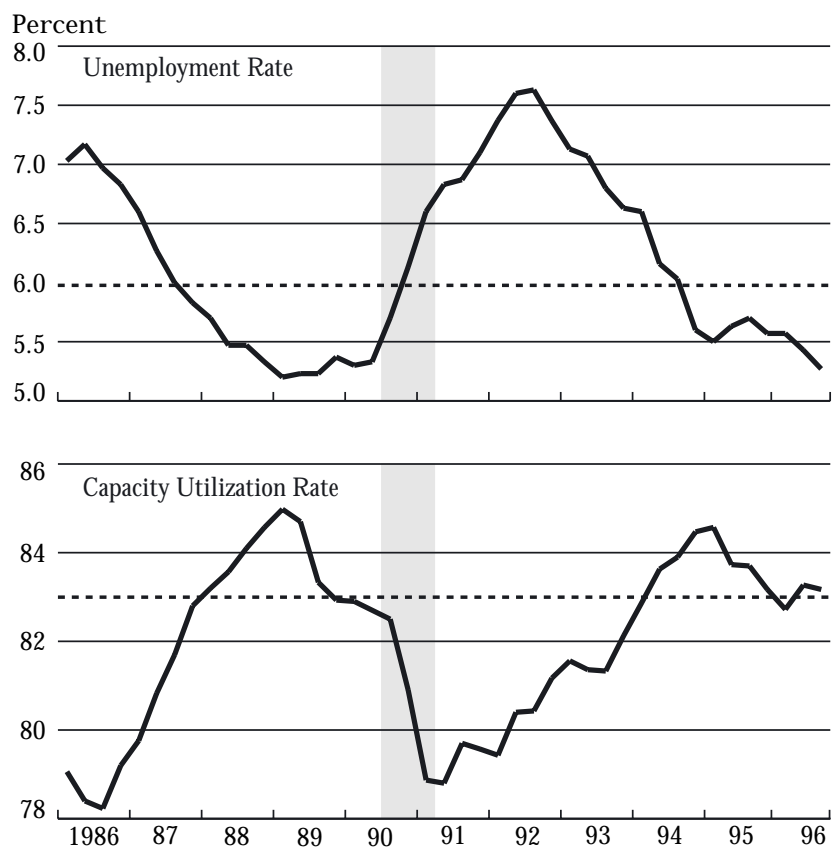

Sources: Board of Governors of the Federal Reserve System; U.S. D epartment of Labor, Bureau of Labor Statistics.

N otes: The dashed line marks the level at which unemployment or capacity utilization will likely begin to exert upward pressure on inflation. The period from the third quarter of 1990 to the first quarter of 1991, shaded in the chart, is designated a recession by the $\mathrm{N}$ ational Bureau of Economic Research. rates in excess of 82 to 84 percent were associated with rising inflation because of the onset of supply shortages and bottlenecks in production (Boldin 1996). Capacity utiliza-

The P hillips curve's recent failure in

forecasting price changes contrasts sharply with

its long-standing reliability in predicting

short-run movements in inflation.

tion has moved down from its peak of almost 85 percent; still, it has stayed above or close to 83 percent since 1994.

Consistent with these two indicators, the Blue Chip Consensus forecast overpredicted inflation from 1992 to 1995 by progressively larger margins of error each year (Chart 3). Estimated priceinflation Phillips curves have also systematically overpredicted inflation in the past couple of years. The Phillips curve's recent failure in forecasting price changes contrasts sharply with its longstanding reliability in predicting short-run movements in inflation. We now turn to a discussion of the Phillips curve and its recent record in forecasting inflation.

Chart 3

CPI Inflation, Actual and Forecast

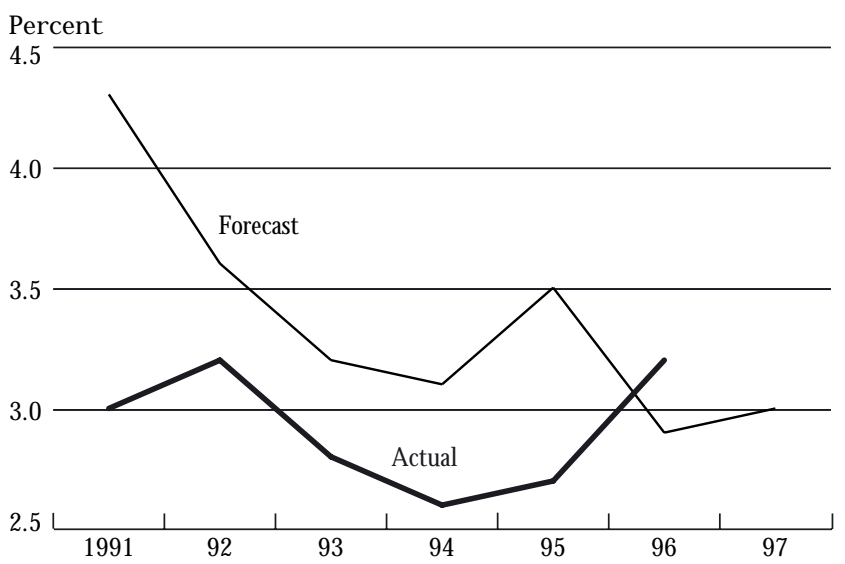

Sources: B lue C hip E conomic Indicators, various December issues; U.S. D epartment of Labor, Bureau of Labor Statistics. 
A TRAditional PRICE-IN FLATION

PHILLIPS CURVE

The origin of the Phillips curve can be traced back to the 1950s, when A.W. Phillips documented an inverse relationship between the rate of change of nominal wages and the level of unemployment in the U nited $\mathrm{K}$ ingdom. $\mathrm{H}$ is findings were interpreted as establishing a wage adjustment process in which low levels of unemployment represent tight labor markets that signal, or coincide with, accelerating wage growth. Although the term "Phillips curve" still refers to the posited relationship between nominal wage or price changes and various indicators of real economic activity, the econometric modeling of this relationship has changed considerably over the years. ${ }^{4}$

Modern versions of the Phillips curve incorporate several features that differentiate them from earlier descriptions of the behavior of nominal wages and prices. ${ }^{5}$ For example, in current models the output gap (the log ratio of

[ Our specification for thetraditional Phillips

curve] embodies the "triangle" model of

inflation: the set of explanatory variables is

meant to capture the effects of demand, inertia,

and supply considerations on inflation.

actual to potential real GDP) and the unemployment gap (the difference between the actual rate of unemployment and the N AIRU) figure importantly as measures of excess aggregate demand pressure in the economy. In addition, current models recognize the role that expected inflation plays in wage bargaining and price setting and typically include past rates of inflation as a proxy for this expectation. ${ }^{6}$ Finally, modern Phillips curve models include variables to control for supply shocks such as the oil price increases of the 1970s. As Fuhrer (1995) notes, many of these developments were anticipated by Phillips in his original discussion.
We begin our empirical analysis by specifying a traditional price-inflation Phillips curve model. The model allows for a more formal investigation of the stability of the Phillips curve relationship during the current expansion. In addition, the model will serve as a benchmark to eval uate compensation growth's role in explaining recent movements in inflation.

Our traditional Phillips curve model is given by:

(1) INF $_{\mathrm{t}}=\alpha_{0}+\alpha_{1}$ GDPGAP $_{\mathrm{t}-1}+\alpha_{2}\left(\triangle \mathrm{GDPAP}_{\mathrm{t}-1}\right)$

$$
+\sum_{i=1}^{3} \alpha_{2+i} \mid N F_{t_{-i}}+\sum_{i=1}^{2} \alpha_{5+i} \text { OIL } G_{t-i}^{+}+\varepsilon_{t} \text {, }
$$

where

IN F = inflation measured by the growth rate of the core CPI,

GDPG A P = the output gap measured by the log ratio of actual to potential real GDP,

$\triangle G D P G A P=$ the first difference or change in the output gap,

OIL $\mathrm{G}^{+}=$the net positive change in the real price of oil, and

$\varepsilon=\mathrm{a}$ mean zero, serially uncorrel ated random disturbance term.

Equation 1 provides a general specification for the rate of change in prices and is similar to other models currently used in the Phillips curveliterature. ${ }^{7}$ In theterminology of Gordon (1996), the specification embodies the "triangle" model of inflation: the set of explanatory variables is meant to capture the effects of demand, inertia, and supply considerations on inflation.

The model uses the output gap (the percentage deviation of real GDP from potential GDP), shown in Chart 4 , as a measure of excess aggregate demand pressure. ${ }^{8}$ A positive (negative) output gap indicates that the economy is operating above (below) potential GDP and would thus generate upward (downward) inflationary pressure on prices. Following the methodology in Gordon (1977, 1996) and Fuhrer (1995), we also include the quarterly change in the output gap variable to allow for a rate-ofchange effect so that the pressure on prices depends on how quickly the output gap narrows or widens. 
The remaining basic determinants of inflation include its own lagged values and oil prices. To incorporate price inertia effects, we include lagged inflation terms in the model. In the past, researchers used lagged inflation rates as a proxy for expected inflation. In modern versions of the Phillips curve, however, this interpretation has been deemed overly restrictive (Gordon 1996). Instead, past inflation rates are viewed as capturing the dynamics of price adjustment related to expectations formation as well as the importance of institutional factors such as wage and price contracts and delivery lags in the economy.

Our benchmark model al so includes a measure of the net positive change in real oil prices to account for the influence of supply shocks. ${ }^{9}$ This oil price variable is the only notable departure from other conventional Phillips curve specifications and allows for an asymmetric effect of oil price changes on inflation (Chart 5). In other words, while oil price increases appear to affect inflation, oil price decreases do not seem to be important. ${ }^{10}$ The construction of the supply shock variable follows the approach in Hamilton (1996) and is designed not only to model the asymmetric effects of oil price changes, but al so to account for the observed increase in the volatility of oil prices over the post-1986 period. Because the core CPI has no energy

\section{Chart 4}

The Output Gap

Percentage Difference between Actual and Potential GDP

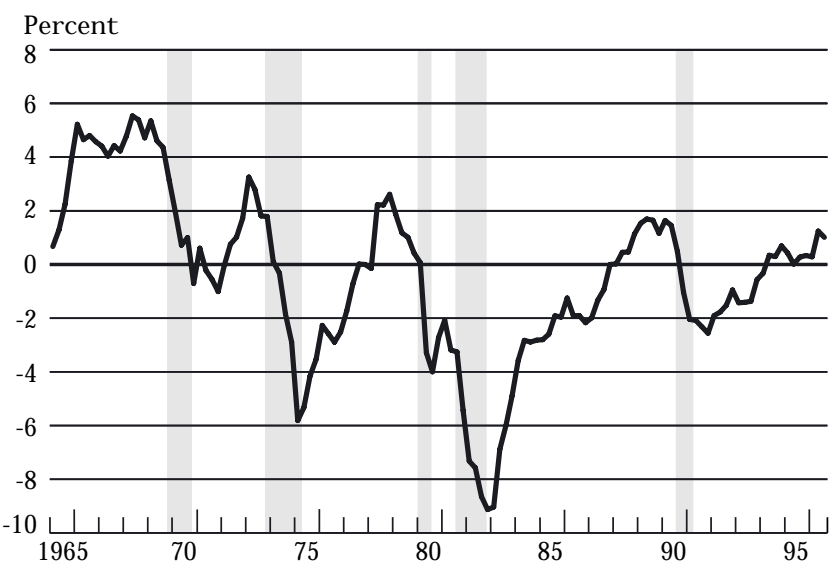

Source: Federal Reserve Bank of $\mathrm{N}$ ew $\mathrm{Y}$ ork staff estimate.

$N$ ote: Shaded areas indicate periods designated recessions by the $N$ ational Bureau of Economic R esearch.
Chart 5

$\mathrm{N}$ et Positive Change in Real Oil Prices

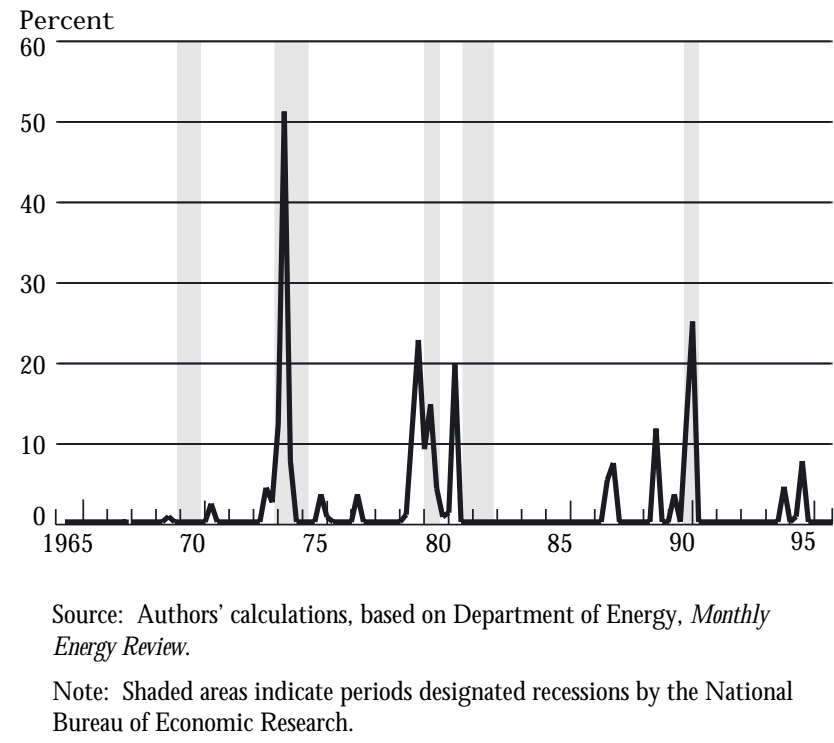

price component, our supply shock variable attempts to capture any indirect effect of oil price increases on inflation.

Although our traditional price-inflation Phillips curve takes real oil prices as exogenous, we include only lagged values of the output gap as regressors in order to avoid simultaneity bias arising from the endogeneity of this variable. The lag lengths in equation 1 are selected by maximizing adjusted $R^{2}$ (a measure of the model's ability to explain inflation), by searching over one to four lags of inflation and the output gap, and by searching over zero to four lags for the net positive change in the real price of oil. ${ }^{11}$

\section{MODEL ESTIMATION}

We estimate equation 1 using the method of ordinary least squares (OLS) for quarterly data from the first quarter of 1965 to the third quarter of 1996. Parameter estimates are presented in Table 1. For the full sample period, the value of the adjusted $R^{2}$ indicates that the model can explain a high proportion of the variation in inflation. In addition, the Ljung-Box (1978) Q-test statistic - a general test for serial correlation in the regression residuals- does not reveal any evidence of model misspecification.

The estimation results also indicate that both the level of the output gap variable and the rate-of-change effect 
Table 1

Traditional and Modified Price-In flation Phillips CURVE MODELS

\begin{tabular}{|c|c|c|c|c|}
\hline \multirow[b]{2}{*}{ Variable } & \multicolumn{2}{|c|}{ Traditional Model } & \multicolumn{2}{|c|}{ Modified Model } \\
\hline & Estimate & \multirow{2}{*}{$\begin{array}{l}p \text {-Value } \\
0.3146\end{array}$} & \multirow{2}{*}{$\begin{array}{c}\text { Estimate } \\
0.0532 \\
(0.0720)\end{array}$} & \multirow{2}{*}{$\begin{array}{c}\mathrm{p} \text {-Value } \\
0.4601\end{array}$} \\
\hline CONSTANT & $\begin{array}{c}0.0786 \\
(0.0782)\end{array}$ & & & \\
\hline $\mathrm{GDPGAP}_{\mathrm{t}-1}$ & $\begin{array}{c}0.0339 * * \\
(0.0107)\end{array}$ & 0.0016 & $\begin{array}{c}0.0190 \\
(0.0108)\end{array}$ & 0.0783 \\
\hline$\Delta G^{\prime} P G A P_{t-1}$ & $\begin{array}{l}0.1452 * * \\
(0.0511)\end{array}$ & 0.0045 & $\begin{array}{c}0.2620 * * \\
(0.0537)\end{array}$ & 0.0000 \\
\hline$I N F_{t-1}$ & $\begin{array}{l}0.4080 * * \\
(0.1209)\end{array}$ & 0.0007 & $\begin{array}{c}0.2610 * \\
(0.1064)\end{array}$ & 0.0142 \\
\hline $\mathrm{NNF}_{\mathrm{t}-2}$ & $\begin{array}{c}0.1296 \\
(0.1168)\end{array}$ & 0.2672 & $\begin{array}{c}0.1252 \\
(0.1046)\end{array}$ & 0.2312 \\
\hline $\mathrm{INF}_{\mathrm{t}-3}$ & $\begin{array}{c}0.3487 * * \\
(0.1227)\end{array}$ & 0.0045 & $\begin{array}{c}0.2913^{* *} \\
(0.1011)\end{array}$ & 0.0040 \\
\hline OILG $_{t-1}$ & $\begin{array}{l}0.0186 * * \\
(0.0056)\end{array}$ & 0.0009 & $\begin{array}{c}0.0167 * * \\
(0.0046)\end{array}$ & 0.0003 \\
\hline OILG $_{t-2}^{+}$ & $\begin{array}{l}0.0242 * * \\
(0.0071)\end{array}$ & 0.0007 & $\begin{array}{l}0.0228 * * \\
(0.0058)\end{array}$ & 0.0001 \\
\hline UN ITG ${ }_{t-1}^{+}$ & - & - & $\begin{array}{c}0.1901 * * \\
(0.0380)\end{array}$ & 0.0000 \\
\hline UNITG ${ }_{t-2}$ & - & - & $\begin{array}{c}0.0732 \\
(0.0390)\end{array}$ & 0.0609 \\
\hline \multicolumn{5}{|l|}{ Memo: } \\
\hline Adjusted $R^{2}$ & \multicolumn{2}{|c|}{0.776} & \multicolumn{2}{|c|}{0.815} \\
\hline Q-test statistic & \multicolumn{2}{|c|}{$\begin{array}{c}22.731 \\
(0.859)\end{array}$} & \multicolumn{2}{|c|}{$\begin{array}{c}27.572 \\
(0.643)\end{array}$} \\
\hline
\end{tabular}

N otes: A symptotic standard errors for the parameter estimates are reported in parentheses and are computed using the procedure of W hite (1980). The Ljung-B ox Q-test statistic for serial correlation of the regression residuals is distributed asymptotically as $\chi^{2}$ with thirty-one degrees of freedom. Probability values for the test statistics are reported in parentheses. * Significant at the 5 percent level.

** Significant at the 1 percent level.

are highly significant and have the expected positive signs. The two lagged values of the net positive change in the real price of oil are also highly significant with the anticipated positive signs. The three lags of the inflation rate are generally significant, and we are unable to reject the hypothesis that the sum of the coefficients equals unity $\left(\alpha_{3}+\alpha_{4}+\alpha_{5}=1\right)$ at conventional significance levels. The latter restriction follows from the natural rate hypothesis and has been previously imposed in the estimation of Phillips curves to make the level of potential output (or the unemployment rate) independent of inflation in the long run.

\section{MOdel Stability OVER THe 1992-96 Period}

We conduct two exercises to examine the stability of the model from 1992 to 1996. First, we apply Chow (1960) split-sample tests to test the null hypothesis of constant parameters against the alternative hypothesis of a onetime shift in the parameters at some specified date. 0 ne test compares the estimates obtained using the data from one subperiod (1965-91) with the estimates using the full sample. ${ }^{12}$ A nother test employs dummy variables for the

Thedynamic simulation provides strong evidence of instability in the traditional price inflation Phillips curve during the current expansion.

entire parameter vector for one subperiod (1992-96) and then tests the joint significance of the dummy variables. ${ }^{13}$ As shown by the reported value of the two test statistics in Table 2, we fail to reject the null hypothesis of parameter stability for the post-1991 period at conventional significance levels. ${ }^{14}$

As a second exercise, we construct dynamic out-of-sample forecasts from the traditional price-inflation Phillips curve. This simulation provides a more stringent test of model stability by relying on lagged predicted values of inflation rather than the lagged actual values of inflation to construct the subsequent one-quarter-ahead forecasts of inflation. In addition, the Chow tests may suffer from low power because they are conducted over a relatively small part of the sample period (1992-96). For this part of the analysis, we estimate equation 1 using data from the first quarter of 1965 through the fourth quarter of 1991. We then use the estimated equation to forecast inflation over the 1992-96 period.

Table2

TRadition AL AN D Modified PHILLIPS CURVE MOdels Chow Test Results for 1992-96

$\begin{array}{lcc}\text { Model } & \text { F-Statistic } & \text { Likelihood Ratio } \\ \text { Statistic }\end{array}$

$\mathrm{N}$ ote: Probability values for the test statistics are reported in parentheses. 
The dynamic simulation provides strong evidence of instability in the traditional priceinflation Phillips curve during the current expansion (Chart 6). Specifically, the out-of-sample forecasts systematically overpredict inflation beginning in the third quarter of 1993. In addition, the forecasted inflation series is characterized by a rising trend and generates prediction errors that increase over time. This excerise is robust to the choice of starting dates. ${ }^{15}$

The results of our dynamic simulation appear to show a shift in the Phillips curve relationship and are consistent with commentators' claims that inflation has remained unexpectedly low during this expansion. We now examine the role of compensation growth in the recent behavior of inflation.

\section{EXAMINING THE ROLE OF COMPENSATION GROWTH}

Because labor costs represent about two-thirds of the total cost of production, some economists have suggested that inflation's recent behavior may be linked to movements in compensation growth and its two components, benefits and wages (Chart 7). Since the end of the 1990-91 reces-

Chart 6

Out -of -Sample Forecast of Core CPI InfIation Traditional Phillips Curve M odel

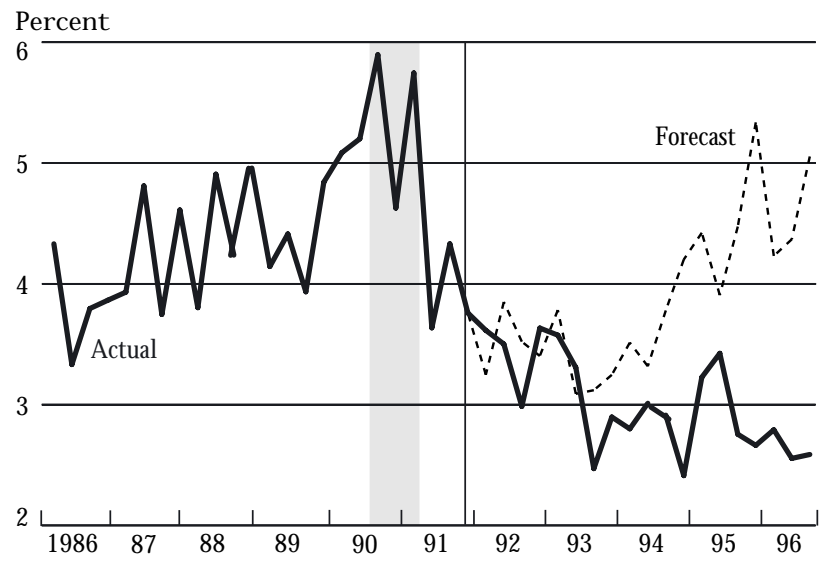

Sources: Authors' calculations; U.S. Department of Labor, Bureau of Labor Statistics.

N ote: The period from the third quarter of 1990 to the first quarter of 1991, shaded in the chart, is designated a recession by the $\mathrm{N}$ ational Bureau of Economic R esearch. sion, the growth rates for total compensation, benefits, and wages have not only failed to display any significant acceleration, but have generally displayed a downward trend. This downward trend is particularly apparent for benefit costs, where the four-quarter change has fallen from 6 percent to about 2 percent during the 1990s. These observed patterns support the view that labor costs may be a key factor in understanding recent movements in inflation.

M eyer (1997), for example, poses two explanations relating compensation growth to inflation's puzzling behavior. First, he suggests that declining benefit costs have caused a temporary slowdown in compensation growth, which has acted as a supply shock. By lowering the increase in overall labor costs, this shock has reduced the pressure on firms to raise prices. Because most priceinflation Phillips curves exclude the effects of compensation growth altogether, their forecasting ability appears to break down and the models overpredict inflation.

Alternatively, Meyer suggests, the slowdown in compensation growth may reflect a long-term change in the behavior of the labor market. In particular, M eyer questions whether heightened job insecurity has permanently diminished workers' ability to obtain wage increases and has consequently altered the link between changes in com-

Chart 7

Empl oyment Cost Index for Private Indust ry Percentage Change from a $Y$ ear Ago

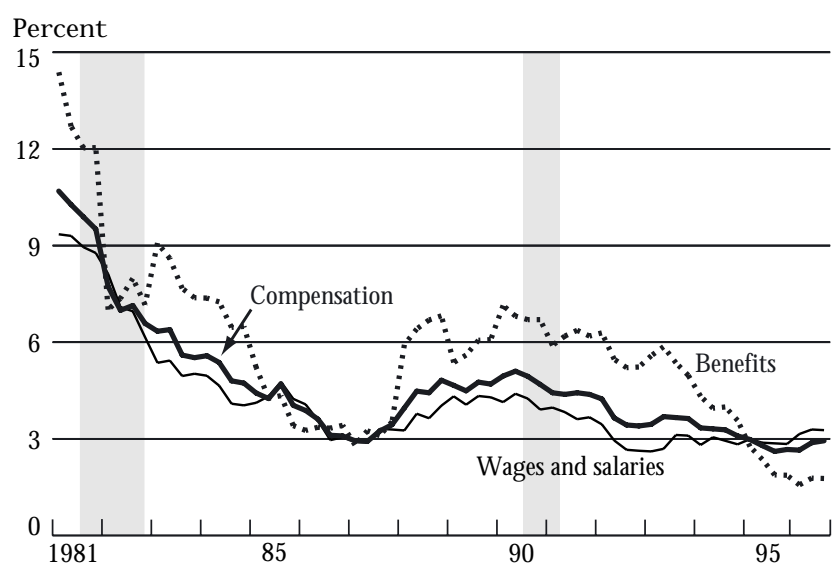

Source: U.S. Department of Labor, Bureau of Labor Statistics. $\mathrm{N}$ ote: Shaded areas indicate periods designated recessions by the $\mathrm{N}$ ational Bureau of Economic R esearch. 
pensation (and other macroeconomic variables) and price changes. According to this view, the recent breakdown in price-inflation Phillips curves reflects a fundamental shift in the inflation process emanating from the labor market. ${ }^{16}$

Although we do not look at the decline in benefit costs or the behavior of wages individual ly, we investigate the role of total compensation growth in restraining infla-

Since the end of the 1990-91 recession, the

growth rates for total compensation, benefits,

and wages have not only failed to display any

significant acceleration, but have generally

displayed a downward trend. This downward

trend is particularly apparent for benefit costs.

tion. ${ }^{17}$ Our methodology is designed to evaluate whether this role has been temporary or permanent in nature.

If compensation growth has acted as a temporary supply shock, we would expect the forecasting performance and the stability of the Phillips curve over the current expansion to be restored by incorporating the effects of compensation growth. M oreover, because a "shock" implies an unexpected event, we would also likely observe some evidence of unusual restraint in the recent behavior of compensation growth. However, if a change in the behavior of compensation growth has permanently al tered the Phillips curve relationship, we should find evidence of a breakdown, rather than stability, in the relationship between the inflation process and compensation growth during the current expansion. We now turn to our modified Phillips curve equation.

\section{Modifying THE TRAdiTiOn AL MOdEL}

Within our Phillips curve framework, we include the growth rate of unit labor costs- compensation (benefits and wages) divided by productivity - as an additional determi- nant of inflation. Unit labor costs provide a measure of compensation that controls for the effects of productivity. ${ }^{18}$

During this expansion, growth in unit labor costs has been weak and a persistent gap has been evident between unit labor cost growth and core CPI inflation (Chart 8). The decline in unit labor cost growth could suggest either falling compensation growth or rising productivity growth. As Chart 9 shows, however, productivity growth has not been unusually strong in the current expansion. Although from late 1991 to early 1992 the series rose at roughly a 3 percent rate, contributing to weaker growth in unit labor costs, since then productivity has typically grown at rates bel ow 1 percent.

By contrast, compensation growth fell to around 2 percent fairly early in the expansion and hovered around that rate for more than two years before showing signs of a modest pickup. This 2 percent growth rate is below any rate recorded in the past thirty-five years. Thus, we can conclude that the growth rate of unit labor costs over the post-1991 period has been primarily driven by slow compensation growth rather than high productivity growth. This finding ensures that our approach will pick up the effect of slow compensation growth, not the effect of high productivity growth, on inflation during this expansion.

Chart 8

Core CPI and Unit Labor Cost S Percentage Change from a $Y$ ear Ago

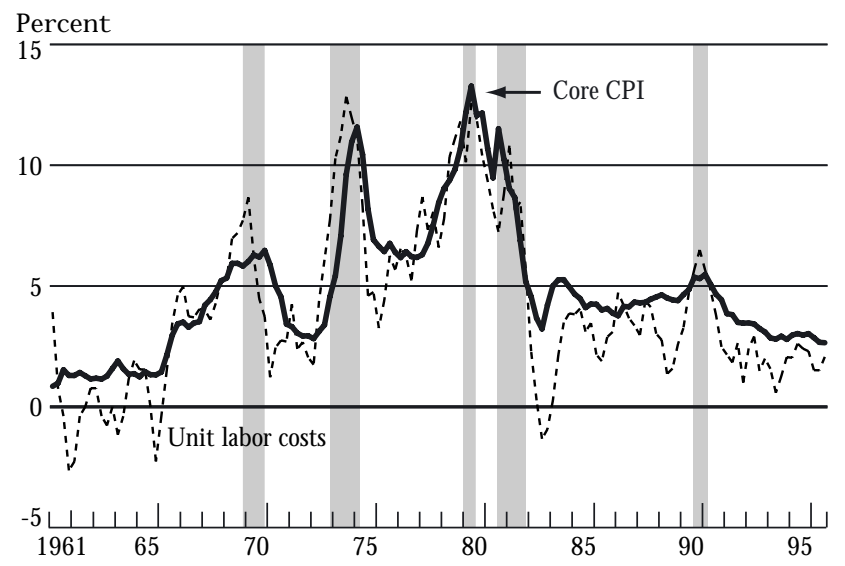

Source: U.S. Department of Labor, Bureau of Labor Statistics. $\mathrm{N}$ ote: Shaded areas indicate periods designated recessions by the $\mathrm{N}$ ational Bureau of Economic Research. 
Our modified price-inflation Phillips curve model is given by:

$$
\begin{aligned}
& \text { (2) IN } \mathrm{F}_{\mathrm{t}}=\alpha_{0}+\alpha_{1} \text { GDPAP }_{\mathrm{t}_{-1}}+\alpha_{2}\left(\triangle \mathrm{GDPGP}_{\mathrm{t}-1}\right) \\
& +\sum_{i=1}^{3} \alpha_{2+i} \mid N F_{t-i}+\sum_{i=1}^{2} \alpha_{5+i} \text { OIL G } t_{t-i}^{+} \\
& +\sum_{i=1}^{2} \alpha_{7+i} \text { UN IT G } G_{t-i}+\varepsilon_{t},
\end{aligned}
$$

where UN ITG is the growth rate of unit labor costs in the nonfarm business sector. In our modified model, unit labor costs provide an explicit channel by which slow compensation growth may have acted to offset other sources of inflationary pressures over the current expansion, resulting in lower inflation rates than those predicted using the traditional model. ${ }^{19}$

\section{MOdEL Estimation}

We estimate equation 2 by the method of OLS using quarterly data from the first quarter of 1965 to the third quarter of 1996. Parameter estimates are presented in Table 1. The two lagged values of unit labor cost growth enter with the anticipated positive sign. The inclusion of the unit labor cost terms improves the fit of the model over

\section{Chart 9}

Productivity and Hourl y Compensation

Percentage Change from a Y ear Ago

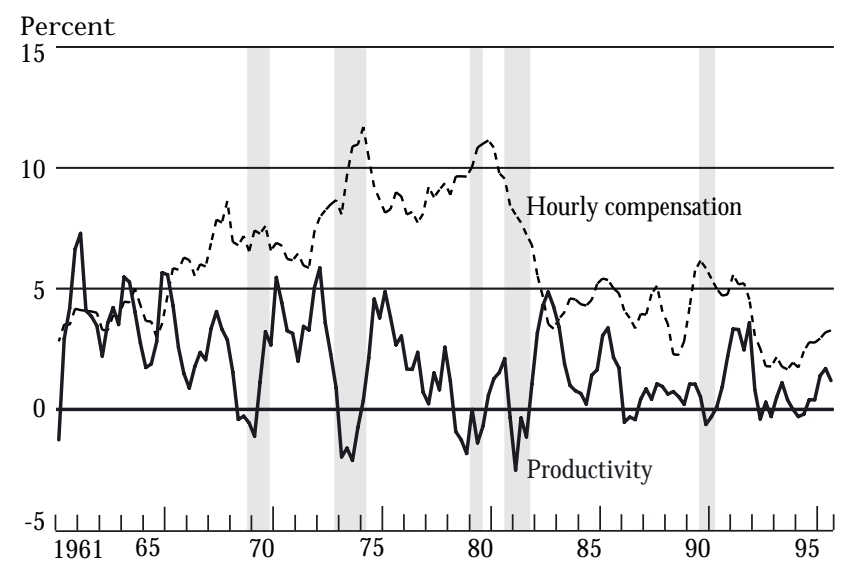

Source: U.S. D epartment of Labor, Bureau of Labor Statistics. $N$ ote: Shaded areas indicate periods designated recessions by the $N$ ational Bureau of Economic R esearch. the full sample period by almost 5 percent relative to the traditional model, and the Q-test statistic does not suggest evidence of model misspecification.

The results for all other explanatory variables are broadly similar across the traditional and modified models, al though the modified Phillips curve suggests that the output gap has a smaller level effect and a larger rate-of-change effect on core CPI inflation. Like the traditional model, the estimated version of the modified model does not constrain the sum of the coefficients on lagged inflation to equal unity $\left(\alpha_{3}+\alpha_{4}+\alpha_{5}=1\right)$. As shown in the Equation A ppendix, however, we can el iminate compensation growth from the system consisting of equation 2 and our estimated wage-inflation Phillips curve to yield a reduced form of a price-inflation Phillips curve. The resulting model is characterized by coefficients on lagged inflation whose sum is not statistically different from unity, and it associates an accel eration in inflation with a positive output gap and a negative unemployment gap.

\section{Model Stability OVer the 1992-96 Period}

Does the inclusion of unit labor costs and the effects of compensation growth correct the instability of our benchmark model over the post-1991 period? An examination of the dynamic simulation for the modified price-inflation Phillips curve suggests that it does (Chart 10). ${ }^{20}$ Once we incorporate the effects of unit labor costs in the model, the simulated values track inflation closely over the post-1991 period and display no significant sign of model instability. Despite a notable error in the fourth quarter of 1995, the equation regains its predictive accuracy over the next two quarters. ${ }^{21}$ Because the dynamic simulation uses forecasted values of inflation, however, the error in the fourth quarter of 1995 continues to affect the subsequent quarters' forecasts and contributes to the error in the third quarter of 1996.

Overall, the evidence from the modified priceinflation Phillips curve is compelling. Indeed, slow compensation growth appears to be a key force in restraining inflation over the current expansion. By including unit labor costs as an additional explanatory 
Chart 10

O ut -of-Sampl e Forecast of Core CPI InfIation

Modified Phillips Curve Model

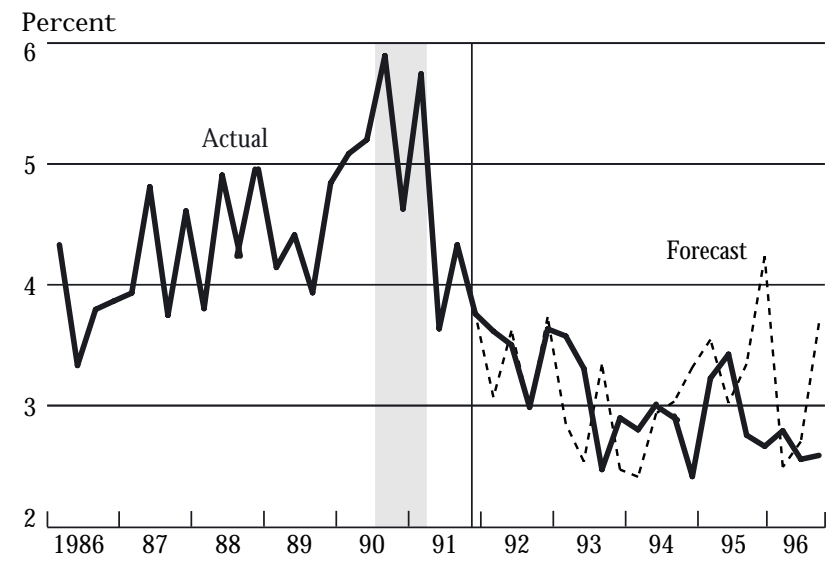

Sources: Authors' calculations; U.S. Department of Labor, Bureau of Labor Statistics.

N ote: The period from the third quarter of 1990 to the first quarter of 1991 , shaded in the chart, is designated a recession by the $\mathrm{N}$ ational Bureau of Economic Research.

variable, the multiperiod forecast performance of the model improves dramatically, and we seem to eliminate the sharp divergence between actual and predicted inflation. Thus, the restored stability of the model resulting from the inclusion of unit labor costs appears to rule out the view that inflation's recent behavior reflects a fundamental shift in the Phillips curve relationship. The analysis, however, has yet to provide any specific insights into compensation growth and its recent behavior. We explore these issues in the next section.

\section{THE BEHAVIOR OF COMPEN SATION GROWTH}

The results from our modified priceinflation Phillips curve reveal compensation growth's role in lowering inflation since 1991. In this section, we anal yze compensation's level of restraint compared with expected levels during the present expansion. The comparison allows us to determine if the recent slowdown in compensation growth has been particularly severe. We show that while restraint in compensation growth appears to be easing, compensation growth was unexpectedly low from late 1992 to early 1995.

To analyze the behavior of compensation growth, we specify a model that represents a modified version of the wage-inflation Phillips curve proposed by Englander and Los (1983):

$$
\begin{gathered}
L X N G_{t}=\beta_{0}+\sum_{i=1}^{2} \beta_{i} L X N G_{t-i}+\beta_{3} U_{t-1} \\
+\sum_{i=1}^{3} \beta_{3+i} I N F_{t-i}+\beta_{7} S O C_{t}+\beta_{8} U I R_{t-1} \\
+\beta_{9} D U M_{t}+\eta_{t}
\end{gathered}
$$

where

$L X N G=$ the growth rate of compensation per hour in the nonfarm business sector,

$U=$ the unemployment rate for males aged twenty-five to fifty-four,

IN F = inflation measured by the growth rate of the CPI (all items, urban consumers),

SOC $=$ the change in employer Social Security contributions,

$U I R=$ the income replacement ratio from unemployment insurance benefits,

D U M = dummy variable for the wage and price controls of the 1970s, and

$\eta=$ a mean zero, serial ly uncorrel ated random disturbance term.

Equation 3 principally links the movements in compensation growth to the unemployment rate and other labor market variables. ${ }^{22}$ The unemployment rate of prime-age males is used as a measure of labor market tightness. We enter the variable in its level form and thereby abstract from any explicit discussion of the N AIRU, except to note that the specification can be viewed as implicitly assuming a constant value for the N AIRU over the sample period. ${ }^{23}$ Equation 3 does not include a rate-of-change effect for the unemployment rate; the estimated coefficient on a second lag of the unemployment rate was found to be quantitatively and statistically insignificant and therefore was omitted from the specification. ${ }^{24}$

The remaining determinants of compensation growth include the change in employer Social Security tax contributions, a component of hourly compensation. The income replacement ratio from unemployment insurance benefits attempts to capture changes in compensation growth related to job search. A dummy variable accounts 
for the restraining effect of wage and price controls in the fourth quarter of 1971 and for the rebound effect after the relaxation of the control sin the first quarter of $1972 .{ }^{25}$ We include lagged values of compensation growth and price

W hile restraint in compensation grow th

appears to be easing, compensation growth

was unexpectedly low from late 1992 to

early 1995.

inflation to incorporate wage and price inertia effects. Finally, we include only lagged values of the unemployment rate and inflation rate as regressors because of endogeneity considerations.

\section{Model Estimation and Model Stability OVER THE 1992-96 PERIOD}

We estimate equation 3 using the method of OLS for quarterly data from the second quarter of 1967 to the third quarter of 1996. The parameter estimates are presented in Table 3. As the table indicates, the lagged values of both compensation growth and price inflation are generally significant. The unemployment rate is highly significant and has the expected negative sign. Further, the variables reflecting other labor market conditions are all significant with the expected signs. The adjusted $\mathrm{R}^{2}$, although not quite as high as the values reported in Table 1, al so indicates that the estimated equation fits the data quite well over the full sample period. In addition, the regression residuals display little evidence of serial correlation over the full sample period.

We al so conduct Chow tests and a dynamic simulation. The Chow tests do not reject the null hypothesis of parameter stability at conventional significance levels (Table 4). For the dynamic simulation, we estimate equation 3 from the second quarter of 1967 to the fourth quarter of 1991; we then use the estimated equation to generate predicted values for compensation growth over the 1992-96 period.

The evidence from the dynamic simulation indicates that compensation growth has displayed unexpected restraint during this expansion. The out-of-sample forecasts consistently overpredict compensation growth beginning in the fourth quarter of 1992 (Chart 11). In addi-

\begin{tabular}{|c|c|c|}
\hline Variable & Estimate & $\mathrm{p}$-Value \\
\hline CONSTANT & $\begin{array}{c}0.3884 \\
(0.2155)\end{array}$ & 0.0715 \\
\hline $\mathrm{LXNG}_{\mathrm{t}-1}$ & $\begin{array}{c}0.1359 \\
(0.0861)\end{array}$ & 0.1144 \\
\hline $\mathrm{LXNG}_{\mathrm{t}-2}$ & $\begin{array}{l}0.2621 * * \\
(0.0689)\end{array}$ & 0.0001 \\
\hline$U_{t-1}$ & $\begin{array}{l}-0.0672 * * \\
(0.0218)\end{array}$ & 0.0021 \\
\hline$I N F_{t-1}$ & $\begin{array}{l}0.2018^{* *} \\
(0.0692)\end{array}$ & 0.0036 \\
\hline$I N F_{t-2}$ & $\begin{array}{c}0.0175 \\
(0.0832)\end{array}$ & 0.8332 \\
\hline$I N F_{t-3}$ & $\begin{array}{c}0.1257 \\
(0.0698)\end{array}$ & 0.0720 \\
\hline $\mathrm{SOC}_{\mathrm{t}}$ & $\begin{array}{c}0.0849 * * \\
(0.0186)\end{array}$ & 0.0000 \\
\hline$U \mid R_{t-1}$ & $\begin{array}{c}1.4288^{*} \\
(0.6666)\end{array}$ & 0.0321 \\
\hline $\mathrm{DUM}_{\mathrm{t}}$ & $\begin{array}{l}-0.7442 * * \\
(0.0790)\end{array}$ & 0.0000 \\
\hline \multicolumn{3}{|l|}{ M emo: } \\
\hline Adjusted $R^{2}$ & 0.709 & \\
\hline Q-test statistic & $\begin{array}{c}28.109 \\
(0.838)\end{array}$ & \\
\hline
\end{tabular}

$\mathrm{N}$ otes: A symptotic standard errors for the parameter estimates are computed using the procedure of W hite (1980) and are reported in parentheses. The Ljung-Box Q-test statistic for serial correlation of the regression residuals is distributed asymptotically as $\chi^{2}$ with twenty-nine degrees of freedom. Probability values for the test statistics are reported in parentheses. * Significant at the 5 percent level.

** Significant at the 1 percent level.

Table 4

COMPENSATION GROWTH MODEL Chow Test Results for 1992-96

\begin{tabular}{lcc} 
Model & F-Statistic & $\begin{array}{c}\text { Likelihood Ratio } \\
\text { Statistic }\end{array}$ \\
\hline $\begin{array}{c}\text { Compensation growth } \\
\text { Phillips curve }\end{array}$ & 0.879 & 20.287 \\
$(0.609)$ & $(0.377)$
\end{tabular}

$\mathrm{N}$ ote: Probability values for the test statistics are reported in parentheses. 
tion, the size of the errors at times is quite large. For example, our dynamic simulation predicts that compensation growth should have been about 2 percent higher from the end of 1992 through the end of 1994. After 1994, however, the size of the forecast errors begins to diminish, a pattern that supports the temporary supply shock hypothesis. If a permanent change in compensation growth had occurred, we would expect the large disparity between the model's simulated values and actual growth to continue, as it did in the traditional price-inflation Phillips curve model.

Evidence from the dynamic simulation corroborates our earlier finding that the modified price-inflation Phillips curve model, which incorporates the effects of compensation growth, appears to resolve the inflation puzzle. The slowdown in compensation growth is most pronounced from the end of 1992 to early 1995, the same period during which the traditional Phillips curve starts to display evidence of model instability. Thus, not surprisingly, variables and relationships that ignore compensa-

Chart 11

O ut-of-Sample For ecast of Compensation Growth

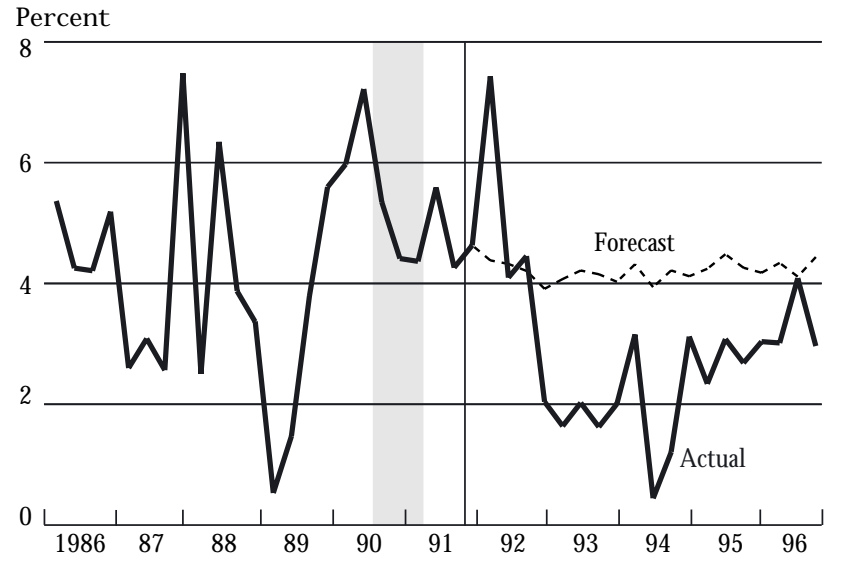

Sources: Authors' cal culations; U.S. Department of Labor, Bureau of Labor Statistics.

$N$ ote: The period from the third quarter of 1990 to the first quarter of 1991 , shaded in the chart, is designated a recession by the $\mathrm{N}$ ational Bureau of Economic R esearch. tion growth's influence (such as the inflation indicators in Charts 2 and 3 and the traditional Phillips curve) begin to break down in late 1993 and 1994.

\section{CONCLUSION}

Contrary to its behavior in previous expansions, price inflation has not accelerated in the six years since the 1990-91 recession. This article focuses on compensation's role in the inflation puzzle, investigating whether a temporary slowdown in compensation growth has lowered the level of inflation or if a more permanent change in compensation growth has fundamentally altered the inflation process. We present two pieces of evidence suggesting that slow compensation growth has acted as a temporary restraining force on inflation.

We begin our investigation by estimating a traditional price-inflation Phillips curve model over the 1965-96 period. Although the model tracks inflation quite well over most of the period, it begins to break down in late 1993. We then modify the traditional Phillips curve model to include the effects of compensation growth. With this addition, the model tracks inflation much more accurately over the current expansion and displays no significant evidence of instability. This finding provides the first piece of evidence suggesting that no fundamental change in the inflation process has occurred.

To arrive at the second piece of evidence supporting the notion that the low level of inflation has resulted from a temporary slowdown in compensation growth, we look at compensation growth itself. By estimating a wageinflation Phillips curve model, we find that compensation growth showed unusual restraint from late 1992 to early 1995. This period of restraint appears to be temporary and coincides with the observed breakdown in the traditional Phillips curve model and in other inflation indicators. Thus, taking compensation growth into account appears to explain inflation's behavior during the current expansion. Still uncertain, however, is the reason for the dramatic slowdown in compensation growth during the early 1990s. The solution to this puzzle must await further investigation. 
This appendix briefly examines the derivation of the accelerationist model of the Phillips curve from equations 2 and 3. The key features of this model can be illustrated by examining the relationship between the output gap (and the unemployment gap with a constant N AIRU) and the inflation rate. Abstracting from the influence of other terms, we note that the system of equations 2 and 3 can be rewritten as

(4)

$$
\begin{gathered}
\text { IN } F_{t}=\alpha_{1} \text { G D PGA } P_{t-1}+\sum_{i=1}^{3} \alpha_{2+i} \mid N F_{t-i} \\
+\sum_{i=1}^{2} \alpha_{7+i}\left(L X N G_{t-i}\right)
\end{gathered}
$$

and

(5)

$$
L X N G_{t}=\frac{\beta_{3} U_{t-1}+\sum_{i=1}^{3} \beta_{3+i} I N F_{t-i}}{\left(1-\beta_{1} L-\beta_{2} L^{2}\right)}
$$

where we substitute for the definition of the growth rate of unit labor costs (compensation growth less productivity growth) in equation 4 , and $L$ denotes the lag operator in equation 5 such that $L^{k} X_{t}=X_{t-k}$.

We can substitute equation 5 into equation 4 to obtain an expression relating current inflation to the output gap, the unemployment gap, and past rates of inflation. If the sum of the coefficients on lagged inflation equals suity, then there is a "natural rate" value of the output gap (and unemployment gap) of zero that is consistent with a constant rate of inflation. Alternatively, the model would associate a permanent positive value for the output gap with an ever-accelerating inflation rate. Within our system of equations, the condition that the sum of the coefficients on lagged inflation equals unity is given by

$$
\alpha_{3}+\alpha_{4}+\alpha_{5}+\left[\frac{\left(\alpha_{8}+\alpha_{9}\right)\left(\beta_{4}+\beta_{5}+\beta_{6}\right)}{\left(1-\beta_{1}-\beta_{2}\right)}\right\rfloor=1 .
$$

The hypothesis that the coefficients on lagged inflation sum to unity can be tested using the OLS estimates of equations 2 and 3 to construct estimates for the expression on the left-hand side of equation 6 and its standard error. The standard error is the standard error of a function of several estimated parameters and can be computed using the delta method approximation ( $G$ reene 1993, p. 297):

$$
\operatorname{SE}[g(\theta)]=\sqrt{\frac{\partial g}{\partial \theta} \cdot \operatorname{VAR}(\theta) \cdot \frac{\partial g}{\partial \theta}},
$$

where $\theta$ denotes the parameters in equation $6, g(\theta)$ is the function of the parameters in 6 , and VAR $(\theta)$ is the variance covariance matrix of those parameters.

Because of the slight disparity in the sample periods for Tables 1 and 2, we estimate equation 2 and equation 3 from the second quarter of 1967 to the third quarter of 1996. The estimate for the expression on the left-hand side of equation 6 is 0.87 , with an estimated standard error of 0.08 . Thus, we are unable to reject the null hypothesis that the sum of the coefficients in equation 6 is equal to unity at the 5 percent significance level. 
This appendix defines the variables and the data sources used to estimate our traditional Phillips curve model, modified Phillips curve model, and compensation growth model. All data in our analysis include revisions through August 12, 1997.

\section{INFLATION EQUATION VARIABLES}

INF = the growth rate of the core CPI for all urban consumers as reported by the Department of Labor, Bureau of Labor Statistics. Data are rel eased monthly and are seasonally adjusted.

UNITG = the growth in unit labor costs for the nonfarm business sector as reported by the Department of Labor, Bureau of Labor Statistics. D ata are released quarterly and are seasonally adjusted.

GDPGAP = the logarithmic ratio of GDP to POTGDP, where GDP equals quarterly real gross domestic product and POT G D P, quarterly potential GDP. Both variables are in 1987 dollars until the third quarter of 1987. They are in chain-weighted 1992 dollars from the fourth quarter of 1987 to the present. The GDP data are from the $\mathrm{N}$ ational Income and Product Accounts. Potential GDP is a Federal Reserve Bank of $\mathrm{N}$ ew York staff estimate.

OILG $^{+}=$the net positive change in the real price of oil, calculated as the percentage change in the current real price of oil from the previous year's maximum (if that change is positive, zero otherwise). D ata for the price of oil are an extension of M ork's (1989) series, which reflects corrections for the effects of price controls during the 1970s. The real price of oil is defined as the nominal oil price index deflated by the GDP deflator.

\section{COMPENSATION EQUATION VARIABLES}

LX N G = the growth rate of compensation per hour for the nonfarm business sector as reported by the Department of Labor, Bureau of Labor Statistics. Compensation comprises wages and salaries for workers plus employers' contributions for Social Security insurance and private benefit plans. The series also includes an estimate of wages, salaries, and supplemental payments for self-employed workers. Data are released quarterly and are seasonally adjusted.

INF = the growth rate of the CPI for all urban consumers as reported by the Department of Labor, Bureau of Labor Statistics. Data are released monthly and are seasonally adjusted.

$\mathbf{U}=$ the unemployment rate for males aged twenty-five to fifty-four as reported by the Department of Labor, Bureau of Labor Statistics. Data are released monthly and are seasonally adjusted.

UIR = unemployment insurance per job loser, normalized by the average annual earnings of a manufacturing worker. This variable can be thought of as a replacement ratio, that is, the fraction of earnings of manufacturing workers replaced by unemployment insurance payments. M anufacturing workers are the most likely workers to collect unemployment insurance. U IR is constructed as (Y PT U I LU J L )/(Y PW F/LAMAN U ), where

Y PT U = government unemployment insurance benefits according to the $\mathrm{N}$ ational Income and Product Accounts. Data are reported quarterly and are seasonal ly adjusted.

LU JL = job losers and persons who have completed temporary jobs as reported by the Department of Labor, B ureau of Labor Statistics. D ata are released monthly and are seasonally adjusted. 
DATA APPEn Dix (Continued)

YPWF = wage and salary disbursements in manufacturing according to the $\mathrm{N}$ ational Income and Product Accounts. Data are reported quarterly and are seasonally adjusted.

LAMANU = nonfarm payroll employees in manufacturing as reported by the Department of Labor, Bureau of Labor Statistics. Data are reported monthly.
SOC = a measure of the direct effect of changes in payroll tax rates for Social Security and Medicare. The quarterly data are Federal Reserve Bank of $\mathrm{N}$ ew York staff estimates.

DUM = 1 in the fourth quarter of 1971, -0.6 in the first quarter of 1972, and 0 elsewhere. This variable accounts for the restraining effect of the wage and price freeze in the fourth quarter of 1971 and the rebound effect after the wage and price controls were relaxed in the first quarter of 1972. 


\section{ENDN OTES}

Theauthors are grateful to J.S. B utler, $G$ abriele $G$ alati, SteveK amin, J onathan $\mathrm{M} \mathrm{CC}$ arthy, Richard Peach, Charles Steinde, and two anonymous referees for he pful comments. W ealso benefited from the suggestions of conference participants at the Bank for International Settlements. B ethika Khan provided excellent research assistance.

1. D ow J ones N ews Service, J anuary 7, 1997.

2. Our analysis expands on results that we presented in two earlier papers. See Lown and Rich (1997a, 1997b).

3. Gordon (1996), however, obtains an estimate of 5.3 percent for the N AIRU starting in 1996.

4. Gordon's work $(1970,1975,1977,1982,1990)$ is prominent in the literature on the estimation of the Phillips curve.

5. See King and W atson (1994), Tootell (1994), Fuhrer (1995), King, Stock, and W atson (1995), and Gordon (1996).

6. The estimation of "expectations-augmented" Phillips curves is the result of work by Phel ps (1967) and Friedman (1968), who devel oped the natural rate hypothesis and drew the distinction between the short-run and long-run Phillips curve trade-off.

7. For detailed definitions and sources of data, see the $D$ ata A ppendix.

8. The results are little affected when the unemployment rate instead of the output gap is used to measure aggregate demand pressure. Potential GDP measures the full-employment level of output or the output level at which there is no tendency for inflation to accel erate or decel erate. The level of potential GDP grows over time because of the increased availability of resources (land, labor force, capital stock, and the level of technology). Because potential GDP is not directly observable, several techniques have been developed to calculate estimates of the series. A complete review of these techniques and an evaluation of the alternative potential GDP series are beyond the scope of this paper. As noted in the DataA ppendix, we employ a staff estimate of potential GDP to construct the output gap variable.

9. Commodity prices and/or an exchange rate term have been used as supply shock variables in some price-inflation Phillips curve models. W e do not include these terms in our specification, however, because we found their effects to be small and statistically insignificant. The absence of a strong link between commodity prices and inflation is consistent with evidence presented by Blomberg and $\mathrm{H}$ arris (1995), who document a recent declinein the predictive power of commodity prices for inflation.
10. W e exclude the net negative real oil price change variable from equation 1 because the variable displays quantitatively and statistically insignificant effects.

11. The compensation growth Phillips curve described later in the text includes dummy variables to capture the effects from the imposition and rel axation of wage and price controls during the 1970s. W e excludethese dummy variables from the traditional price-inflation Phillips curve because they were found to be statistically insignificant. Alternative dating schemes for the dummy variables (Gordon 1982) also proved to be unimportant in explaining the dynamics of inflation during the 1971-75 period.

12. This test yields an F-statistic, which is distributed asymptotically as $F$ with $(m, n-k)$ degrees of freedom under the null hypothesis. The values of $n$ and $n+m$ refer to the number of observations in the first subperiod and the total sample, respectively. The val ue of $k$ refers to the number of parameters in the model.

13. This test yields a likelihood ratio statistic, which is distributed asymptotically as chi-square with $k$ degrees of freedom under the null hypothesis.

14. We also looked for evidence of parameter instability using the CUSU M and CUSU MSQ tests proposed by Brown, Durbin, and Evans (1975). The tests are based on recursive residuals, with the CU SU M test primarily used to detect gradual structural change and the CU SU M SQ test used to detect sudden structural change. The tests provided no evidence of parameter instability.

15. The dynamic simulation yielded similar results for the 1994-96 period.

16. M eyer (1997) notes that the declines in computer prices and import prices over the current expansion may also be acting as temporary supply shocks helping to restrain inflationary pressures in the economy. Moreover, as an additional explanation for the inflation puzzle, he cites firms' inability to raise prices because of increased international competitive pressures. W e do not address these factors in this paper and instead restrict our attention to the two explanations that concern labor market phenomena. Further, while our analysis is not exhaustive, we neverthel ess believe that it is instructive to evaluate these explanations before considering al ternative hypotheses.

17. Our focus on compensation growth is also motivated by the idea that the pricing decision of a firm should be based on a consideration of its total labor costs rather than the behavior of the wage and benefit 


\section{ENDN OTES (Continued)}

N ote 17 continued

components of these costs. In addition, the data preclude us from obtaining observations on wages and benefits separately over the full sample period. The employment cost index, which provides measures of wages and benefits, is only available beginning in 1980 for the nonfarm sector.

18. W e modify the traditional price-inflation Phillips curve to include unit labor costs rather than compensation per hour because it is the behavior of compensation growth relative to productivity growth that is relevant for describing the dynamics of the inflation process. That is, greater productivity growth will act to offset the inflationary pressure on prices arising from an increase in compensation growth.

19. N ote that our model does not allow us to examine whether a shift in the Federal Reserve's inflation fighting credibility has changed the inflation process by directly altering inflation expectations. Such an examination is beyond the scope of this paper and would involve estimating a separate equation for inflation expectations and including some measure of Federal Reserve credibility as an explanatory variable. Previous evidence, however, suggests that such a shift has not taken place. Blanchard (1984) notes that similar types of Phillips curves remained stable even after the 1979 change in Federal Reserve operating procedures.
20. As the val ue of the test statistics in Table 2 indicates, the Chow tests fail to reject the null hypothesis of parameter stability at conventional significance levels. H owever, this result is not particularly informative because the Chow tests al so failed to reject the null hypothesis of model stability for the traditional Phillips curve.

21. The increase in the forecasted value for inflation primarily reflects the influence of a change in the output gap and the oil price variable.

22. For definitions of the data and their sources, see the D ata A ppendix.

23. For example, we could follow the approach of Fuhrer (1995), who assumes a val ue of 6 percent for the N AIRU, and use the unemployment gap (the difference between the actual level of unemployment and the $\mathrm{N}$ AIRU ) instead of the unemployment rate as an explanatory variable in equation 3. This approach, however, would not affect the regression results other than to change the estimated value of the constant term.

24. Fuhrer (1995) also finds an absence of significant rate-of-change effects for the unemployment rate in wage-inflation Phillips curve models.

25. The definition of the dummy variable is from Englander and Los (1983). 
Blanchard, Olivier J. 1984. "The Lucas Critique and the Volcker Deflation." American Economic Review 74, no. 2: 211-5. Papers and Proceedings of the 96th Annual Meeting of the American Economic Association, December 1983.

B lomberg, S. B rock, and Ethan S. H arris. 1995. "The CommodityConsumer Price Connection: Fact or Fable?" Federal Reserve Bank of N ew York ECONomic Policy Review 2, no. 2: 21-38.

Boldin, M ichaed D. 1996. "Problems in Determining the CapacityInflation Link." U npublished manuscript, the Conference Board.

B rown, R.L., J. D urbin, and J.M. Evans. 1975. "Techniques for Testing the Constancy of Regression Relationships over Time." J OURNAL OF the ROyal Statistical SOCIETy 37: 149-92.

Chow, G regory C. 1960. "T ests of Equal ity between Sets of Coefficients in Two Linear Regressions." Econ OMETRICA 28: 591-605.

Eggert, R obert, ed. 1991-95. BLUE CHIP ECON OMIC I N DICATORS. Capitol Publications, Inc.

Englander, Steven A., and Cornelis A. L os. 1983. "The Stability of the Phillips Curve and Its Implications for the 1980s." Federal Reserve Bank of N ew Y ork R esearch Paper no. 8303, February.

Friedman, M ilton. 1968. "The Role of Monetary Policy." American ECONOMIC REVIEW 58: 1-17.

Fuhrer, Jeff. 1995. "The Phillips Curve Is Alive and W ell." Federal Reserve Bank of Boston N EW EN GLAN D ECON OMIC REVIEW, MarchApril: 41-56.

Goodfriend, M arvin. 1993. "Interest Rate Policy and the Inflation Scare Problem: 1979-1992." Federal ReserveBank of Richmond Q UARTERLY REVIEW 79, no. 1: 1-24.

G ordon, R obert J. 1970. "The Recent Acceleration of Inflation and Its Lessons for the Future." BROOKINGS PAPERS ON ECONOMIC ACTIVITY, no. 1: 8-41.

- - . 1975. "The Impact of Aggregate Demand on Prices." BROOKINGS PAPERS ON ECONOMIC ACTIVITY, no. 3: 613-62.

- - . 1977. "Can the Inflation of the 1970s Be Explained?" BROOKINGSPAPERS ON ECONOMIC ACTIVITY, no. 1: 253-77.

- - . 1982. "Inflation, Flexible Exchange Rates, and the $\mathrm{N}$ atural Rate of U nemployment." In Baily, M.N ., ed., W ORKERS, J OBS AN D IN FLATION, pp. 88-152. W ashington, D.C.: Brookings Institution.
- - . 1990. "U.S. Inflation, Labor's Share, and the $N$ atural $R$ ate of Unemployment." In König, Heinz, ed., ECONOMICS OF WAGE DeterminATION, pp. 1-34. Berlin and N ew Y ork: Springer-Verlag.

- - . 1996. "The TimeV arying N AIRU and Its Implications for Economic Policy." N ational Bureau of Economic Research W orking Paper no. 5735, August.

Greene, W illiam H. 1993. Econometric Analysis. New York: Macmillan Publishing Company.

H amilton, James D. 1996. "This Is W hat Happened to the Oil PriceMacroeconomy Relationship." J OURNAL OF MONETARY ECONOMICS 38, no. 2: 215-20.

King, R obert G ., and M ark W . W atson. 1994. "The Post-W ar U.S. Phillips Curve: A Revisionist Econometric H istory." CARnegIe-RoChester Conferen Ce Series on Public Policy 41 (December): 157-219.

King, R obert G., James H. Stock, and M ark W. W atson. 1995. "Temporal Instability of the Unemployment-Inflation Relationship." Federal Reserve Bank of Chicago Econ omic Perspectives 19, no. 3 (M ayJ une): 2-12.

L jung, G.M ., and G .E.P. B ox. 1978. "On a M easure of Lack of Fit in Time Series Models." BIOMETRIKA 67: 297-303.

Lown, Cara S., and Robert W. Rich. 1997a. "A Look at the U.S. Inflation Puzzle." In Monetary Policy and the In flation Process. Bank for International Settlements CON FEREN CE PAPERS 4 (J uly).

- - . 1997b. "Is There an Inflation Puzzle?" Federal Reserve Bank of N ew Y ork Research Paper no. 9723.

M eyer, Laurence H. 1997. "The Economic O utlook and Challenges for Monetary Policy." Remarks delivered to the Charlotte Economics Club on January 16, Charlotte, N.C.

M ork, K nut A . 1989. "Oil and the Macroeconomy W hen Prices Go Up and Down: An Extension of Hamilton's Results." JOURNAL OF Political ECONOMy 97, no. 3: 740-4.

Phelps, Edmund S. 1967. "Phillips Curves, Expectations of Inflation, and Optimal U nemployment over Time." ECON OMICA 34: 254-81.

Phillips, A.W . 1958. "The Relation between U nemployment and the Rate of Change of M oney W age R ates in the U nited K ingdom, 18611957." ECONOMICA 25: 283-300. 


\section{ReFEREN CES (C ontinued)}

T ootell, G eoffrey M.B. 1994. "Restructuring, the NAIRU, and the Phillips Curve." Federal Reserve Bank of Boston N EW ENGLAND Econ OMIC ReVIEW, September-O ctober: 31-44.
W hite, $\mathrm{H}$ albert. 1980. "A Heteroskedasticity-consistent Covariance Matrix Estimator and Direct Test for Heteroskedasticity." ECONOMETRICA 48, no. 4: 817-38.

The views expressed in this article are those of the authors and do not necessarily reflect the position of the Federal Reserve Bank of New York or the Federal Reserve System. The Federal Reserve Bank of New York provides no warranty, express or implied, as to the accuracy, timeliness, completeness, merchantability, or fitness for any particular purpose of any information contained in documents produced and provided by the Federal Reserve Bank of New York in any form or manner whatsoever. 